\title{
Protocol
}

\section{The Primer Extension Assay}

\author{
Michael F. Carey, Craig L. Peterson, and Stephen T. Smale
}

In the primer extension assay, the transcription start site for a gene is determined experimentally by identifying the $5^{\prime}$ end of the encoded messenger RNA (mRNA). The protocol begins with a primer, usually a synthetic oligonucleotide of about 20 residues, that is complementary to an mRNA sequence $\sim 50-150$ nucleotides downstream of the anticipated $5^{\prime}$ end. The primer is $5^{\prime}$-end-labeled using $\left[\gamma^{-32} \mathrm{P}\right]$ ATP and T4 polynucleotide kinase and is annealed to the specific mRNA molecules within an RNA sample. Reverse transcriptase (RT), deoxyribonucleoside triphosphates, and appropriate buffer components are added to the primer-mRNA hybrids to catalyze elongation of the primer to the $5^{\prime}$ end of the mRNA. The resulting radiolabeled complementary DNA (cDNA) products are analyzed by denaturing polyacrylamide gel electrophoresis, followed by autoradiography. The sizes of the bands detected on the gel, as compared to an adjacent sequencing ladder or molecular weight standards, provide a measure of the distance from the $5^{\prime}$ end of the synthetic oligonucleotide to the beginning of the mRNA transcripts. In theory, the $3^{\prime}$ end of the cDNA will coincide with the $5^{\prime}$ end of the mRNA. Thus, the size of the radiolabeled cDNAs should represent the distance from the labeled $5^{\prime}$ end of the primer to the $5^{\prime}$ end of the mRNA (i.e., the $3^{\prime}$ end of the cDNA). If the labeled cDNA products are within the resolution range of the gel, the transcription start site can be determined with an accuracy of plus or minus one nucleotide.

It is essential that you consult the appropriate Material Safety Data Sheets and your institution's Environmental Health and Safety Office for proper handling of equipment and hazardous materials used in this protocol.

RECIPES: Please see the end of this article for recipes indicated by $<R>$. Additional recipes can be found online at http://cshprotocols.cshlp.org/site/recipes.

\section{Reagents}

Actinomycin D (optional; see Step 23)

Prepare a stock solution of $5 \mathrm{mg} / \mathrm{mL}$ actinomycin $D$ in ethanol. Store in the dark at $-20^{\circ} \mathrm{C}$. Add to RT buffer immediately before use. Alternatively, solutions of mannitol-solubilized actinomycin D (Sigma) can be prepared and stored as above.

Denaturing polyacrylamide sequencing gel $(8 \%)$

Dry ice

Ethanol

Formamide loading dye

Adapted from Transcriptional Regulation in Eukaryotes: Concepts, Strategies, and Techniques, 2nd edition, by Michael F. Carey, Craig L. Peterson, and Stephen T. Smale. CSHL Press, Cold Spring Harbor, NY, USA, 2009.

(C) 2013 Cold Spring Harbor Laboratory Press

Cite this article as Cold Spring Harb Protoc; 2013; doi:10.1101/pdb.prot071902 


\section{Equipment}

$\left[\gamma^{3}{ }^{32} \mathrm{P}\right] \mathrm{ATP}$, high-specific-activity (>5000 Ci/mmol; $\left.10 \mathrm{mCi} / \mathrm{mL}\right)$

Moloney murine leukemia virus (MMLV) reverse transcriptase

We find that the cloned MMLV SuperScript III RT from Invitrogen works well (see Discussion). Other reverse transcriptases, such as avian myeloblastosis virus (AMV) reverse transcriptase are commonly used, but require different reaction buffers.

$\mathrm{NaCl}(5 \mathrm{M})$

$\mathrm{NaOH}(0.1 \mathrm{~m})$

Oligonucleotide, purified (see Discussion)

Purified synthetic oligonucleotides are commonly used as primers and are typically labeled efficiently by T4 polynucleotide kinase. To enhance the efficiency of the kinasing reaction, contaminants should be removed from the synthetic oligonucleotide preparation by gel or column purification. The concentration can then be determined from the $O D_{260}$ of a diluted sample.

Primer extension (PE) buffer $(5 \times)<\mathrm{R}>$

Reverse transcription (RT) buffer $<\mathrm{R}>$

RNA of interest (total or poly $(\mathrm{A})^{+}$mRNA)

Sodium acetate (3 $\mathrm{M}, \mathrm{pH}$ 5.2)

STE buffer for primer extension $<\mathrm{R}>$

T4 PNK buffer $(10 \times)<\mathrm{R}>$

T4 polynucleotide kinase (10 Units/ $\mu \mathrm{L})$

TE buffer

Column, probe purification (e.g., NucTrap; Stratagene)

Evaporator, SpeedVac

Intensifying screen (optional)

Microcentrifuge

Microcentrifuge tubes

Phosphorimager (optional)

Push Column Beta Shield Device (Stratagene, 400700)

Scintillation counter

Syringe, $\mathrm{BD}$ with a Luer-Lok tip $\left(10 \mathrm{~cm}^{3}\right)$

Tissues

X-ray film (e.g., XAR-5 film; optional)

Stage 1: Kinase the Purified Oligonucleotide Primer (2 h)

1. Mix $5 \mu \mathrm{L} 10 \times \mathrm{T} 4$ PNK buffer with 2.5 picomoles of purified oligonucleotide and $5 \mu \mathrm{L}(\sim 10$ pmoles) of $\left[\gamma_{-}{ }^{32} \mathrm{P}\right] \mathrm{ATP}$. Add $\mathrm{dH}_{2} \mathrm{O}$ to a final volume of $49 \mu \mathrm{L}$.

2. Add $1 \mu \mathrm{L}$ (10 Units) of T4 polynucleotide kinase.

3. Incubate for $45-60 \mathrm{~min}$ at $37^{\circ} \mathrm{C}$.

4. Heat-inactivate the kinase for $10 \mathrm{~min}$ at $68^{\circ} \mathrm{C}$. 
M.F. Carey et al.

\section{Stage 2: Remove Unincorporated $\left[\gamma_{-}{ }^{32} \mathrm{P}\right]$ ATP (30 min)}

Unincorporated $\left[\gamma_{-}^{32}\right.$ PJATP molecules should be removed from the primer preparation to prevent them from interfering with the primer extension reactions and, in particular, with gel electrophoresis and autoradiography. Unincorporated nucleotides can be removed by differential ethanol precipitation in the presence of ammonium acetate (see Purification of Radiolabeled Oligonucleotides by Precipitation with Ethanol [Sambrook and Russell 2006]) or by column chromatography (as described here).

5. Add $1 \mu \mathrm{L}$ of $5 \mathrm{M} \mathrm{NaCl}$ to the heat-inactivated reaction sample.

6. Prewash a Stratagene NucTrap column by applying $70 \mu \mathrm{L}$ of STE buffer.

7. Extend the plunger of a $10-\mathrm{cm}^{3} \mathrm{BD}$ syringe with a Luer-Lok tip and screw the syringe onto the column to form a seal between the column and the syringe according to the manufacturer's protocol. Do not screw the syringe on too tightly.

8. Force the buffer down the length of the column until a small drop exits at the end. Use the prewetted column within 5-10 min.

9. Attach the column to the Beta Shield according to the manufacturer's instructions.

10. Apply the radioactive solution to the column, attach the extended syringe, and slowly (25-35 sec) push the sample through the column with the plunger. Collect the flowthrough in a microfuge tube. The unincorporated nucleotides will remain in the resin and the radiolabeled primer will pass through the column into the tube.

11. Apply $70 \mu \mathrm{L}$ of STE solution to the column, push through with the syringe, and collect the flowthrough in the same tube.

12. Dilute the primer solution with an additional $140 \mu \mathrm{L}$ of STE buffer.

13. Quantitate the radioactivity by scintillation counting (Cerenkov counting; i.e., in the absence of scintillation fluid). Cerenkov measurements vary from machine to machine, but roughly $50,000-100,000 \mathrm{cpm}$ per $\mu \mathrm{L}$ should be obtained in the final primer solution.

See Troubleshooting.

14. Store the primer at $-20^{\circ} \mathrm{C}$. It can usually be used for up to $1 \mathrm{mo}$.

Stage 3: Make Buffers for Primer Annealing and Extension (30 min)

Nuclease-free buffers and reagents and RNase inhibitors can be used for primer extension reactions, but they generally are not necessary. Extensive degradation would be needed to affect the results of a primer extension assay noticeably, because only the $5^{\prime}$ end of each mRNA molecule needs to be intact for the primer extension assay to succeed.

15. Prepare $5 \times \mathrm{PE}$ buffer and RT buffer (store at $-20^{\circ} \mathrm{C}$ ).

Stage 4: Primer Extension (3-4 h)

Negative control RNAs should be included whenever possible and are essential for mapping unknown start sites. A tRNA or yeast RNA control yields less information but can be used as an additional control. Ideally, negative control RNA should be prepared from a cell line or tissue that does not express the RNA being measured and, ideally, this cell line should be from the same species as the experimental RNA. If possible, RNAs prepared from multiple positive and negative cell lines or tissues should be tested. Without appropriate negative controls, mapping of a novel start site will be less compelling.

16. Add $1 \mu \mathrm{L}$ of radiolabeled primer ( $~ 50,000-100,000 \mathrm{cpm}$ as measured by Cerenkov counting) to $10-60 \mu \mathrm{g}$ of total RNA (or $\sim 2-5 \mu \mathrm{g}$ of poly $(\mathrm{A})^{+} \mathrm{mRNA}$ ). The optimal amount of RNA to use for a primer extension reaction will vary and may need to be determined empirically. In general, the success of the procedure is less dependent on the amount of RNA than on other variables, such as the specific activity of the primer, the annealing temperature, and the presence or absence of RNA secondary structures. During initial experiments, $30 \mu \mathrm{g}$ of total cellular RNA or total cytoplasmic RNA is an appropriate amount to use. 
17. Add $3 \mathrm{~m}$ sodium acetate ( $\mathrm{pH}$ 5.2) to a concentration of $0.3 \mathrm{M}$, followed by 2.5 volumes of ethanol. Incubate in dry ice for $10 \mathrm{~min}$ or at $-20^{\circ} \mathrm{C}$ for $30 \mathrm{~min}$ to precipitate the RNA and primer.

18. Pellet the RNA and primer by centrifugation at $14,000 \mathrm{~g}$ for $10 \mathrm{~min}$ in a microfuge.

19. Carefully remove the supernatant and dry the pellet in a SpeedVac or by evaporation on the bench top. Virtually all of the radioactivity should be present in the pellet, with trace amounts in the supernatant.

See Troubleshooting.

20. Suspend the dried pellet in $8 \mu \mathrm{L}$ of TE buffer. The pellet will not suspend in this small volume of buffer by vortexing because the buffer will not remain at the bottom of the tube. The preferred method for pellet suspension is to "flick" the bottom of the tube repeatedly with one's finger. Alternatively, the pellet can be dissolved by repetitive pipetting of the solution with a pipetman.

21. Add $2 \mu \mathrm{L}$ of $5 \times$ PE buffer to the tube. Mix and centrifuge briefly.

The $5 \times$ PE buffer should not be added until the RNA has dissolved in the TE because the RNA will dissolve much more slowly in the high-salt PE buffer.

22. Anneal the primer to the RNA by incubating $90 \mathrm{~min}$ at the empirically determined temperature. During the incubation, centrifuge the samples briefly every $20 \mathrm{~min}$, so that the solution does not condense at the top of the tube.

A good starting point is to test temperatures of $37,45,60$, and $68^{\circ} \mathrm{C}$. Some primers work well if the hybridization reactions are first heated to $68^{\circ} \mathrm{C}$, then allowed to cool slowly to room temperature in a metal block.

23. Prepare a solution containing $39.5 \mu \mathrm{L}$ of RT buffer and $0.5 \mu \mathrm{L}$ of MMLV reverse transcriptase per each reaction. Optionally, add $50 \mu \mathrm{g} / \mathrm{mL}$ actinomycin D to the RT buffer. Since Pipetmen are not perfectly accurate, it is best to make up a larger amount of the solution than is needed.

Actinomycin D inhibits the synthesis of double-stranded DNA by reverse transcriptases and is sometimes included in the reverse transcriptase reactions to prevent the synthesis of hairpin molecules. Hairpin molecules are rarely a problem with short synthetic oligonucleotide primers, unless the expected extension products are also very short.

24. Add $40 \mu \mathrm{L}$ of RT mix to each reaction tube. Mix, but do not vortex. Centrifuge briefly.

25. Incubate for $60 \mathrm{~min}$ at $37^{\circ} \mathrm{C}$. Higher temperatures (e.g., $42,45,55^{\circ} \mathrm{C}$ ) can be used in an attempt to diminish unwanted effects of the RNA secondary structure.

26. Stop the reaction and precipitate the nucleic acids by adding $6 \mu \mathrm{L}$ of $3 \mathrm{~m}$ sodium acetate and $150 \mu \mathrm{L}$ of ethanol. Vortex well. Chill on dry ice for $10 \mathrm{~min}$ or at $-20^{\circ} \mathrm{C}$ for $30 \mathrm{~min}$.

27. Centrifuge for $10 \mathrm{~min}$. A small white pellet should be visible on the bottom of the tube. Remove the ethanol. Blot the top of the tube on a Kimwipe to remove excess liquid. Most of the radioactivity should remain in the pellet.

28. Dry the pellet well in a SpeedVac evaporator.

Stage 5: Denaturing Polyacrylamide Gel Electrophoresis (2-3 h)

29. Suspend the pellet in $4 \mu \mathrm{L}$ of formamide loading dye and $2 \mu \mathrm{L}$ of $0.1 \mathrm{~m} \mathrm{NaOH}$.

At this point, the amount of radioactivity in each tube should still be similar to the amount added to the reactions in Step 16: If the amount is less, the precipitations probably did not work well or the pellets were lost.

30. Boil for 2 min to denature the DNA/RNA hybrids. Centrifuge briefly.

31. Load $3 \mu \mathrm{L}$ of each sample onto an $8 \%$ denaturing polyacrylamide sequencing gel, after rinsing the wells of the gel.

32. Run the gel until the bromophenol blue dye is near the bottom. (The goal is to have the excess labeled primer migrate near the bottom of the gel.) 
M.F. Carey et al.

Stage 6: Product Analysis

33. Dry the gel and expose it to XAR-5 film in the presence of an intensifying screen, or analyze on a phosphorimager. Strong signals on a film should be detectable with an overnight exposure.

See Troubleshooting.

TROUBLESHOOTING

Problem (Step 13): There is poor yield of radiolabeled primer.

Solution: Consider the following:

1. There may be a problem with the reagents (e.g., kinase may be inactive, radiolabeled ATP may be hydrolyzed, T4 PNK buffer may be improperly prepared, or DTT may be oxidized). Test new reagents. Use a more rigorous method of quantitating incorporation of ${ }^{32} \mathrm{P}$ (Sambrook and Russell 2001, pp. A8.25-A8.26).

2. Oligonucleotide may contain excess contaminants or quantitation may be inaccurate. Purify a new aliquot of oligonucleotide or confirm concentration. Compare yields with the yields obtained using another oligonucleotide. Use a different method of purifying oligonucleotide. Use a more rigorous method of quantitating incorporation (Sambrook and Russell 2001, pp. A8.25-A8.26).

3. The method of removing unincorporated ATP may result in loss of radiolabeled primer. Repeat procedure. Try a different method of removing unincorporated nucleotides.

Problem (Step 19): Most radioactivity remains in supernatant following ethanol precipitation.

Solution: Consider the following:

1. Unincorporated ATP may have been inefficiently removed during Step 10. Repeat Step 10 with remaining preparation of radiolabeled primer. Try a different method of removing unincorporated nucleotides.

2. Ethanol precipitation of radiolabeled primer may have been inefficient. Mix ethanol/primer/ RNA solution more thoroughly before chilling. Chill on dry ice for a longer amount of time. Add another 0.5 volume of ethanol. Add another $0.1 \mathrm{~m}$ sodium acetate.

3. Pellet may have been poured off into supernatant. Centrifuge supernatant again and try to detect the pellet when removing the supernatant. Remove the supernatant with a drawn-out Pasteur pipette.

Problem (Step 33): The gel image shows a strong primer signal at the bottom of the gel, but no extension products or only very short extension products that are also present in negative controls.

Solution: Consider the following:

1. There may have been inefficient annealing to specific mRNA.Try different annealing temperatures. Try different annealing buffer components, such as formamide. Try different primers that anneal to slightly distal or proximal sequences. In some cases, several different primers need to be tested to find one that anneals efficiently. The reasons for inefficient annealing of some primers are not known.

2. There may be inefficient extension by reverse transcriptase. Use a higher concentration or a different batch of reverse transcriptase. Prepare a new batch of reverse transcription buffer. Perform reverse transcription reactions at a higher temperature to reduce mRNA secondary 
structures. Check the $\mathrm{pH}$ of reaction buffer (in particular for the avian enzyme, which is sensitive to $\mathrm{pH}$ ).

3. Concentration of specific mRNAs may be too low to detect. Try using more mRNA for the experiment. Try purified polyadenylated mRNA. Try a method of mapping the transcription start site that is potentially more sensitive, such as the RNase protection method or RACE.

Problem (Step 33): It is difficult to distinguish specific cDNA products from background. Solution: Consider the following:

1. Primer may be hybridizing to other RNAs in the sample. Try higher annealing and/or extension temperatures. Try a different primer complementary to a slightly proximal or distal sequence. Confirm start site using a different method, such as RNase protection, S1 nuclease analysis, or rapid amplification of cDNA ends (RACE). Try using less reverse transcriptase.

2. There may be inefficient extension by reverse transcriptase. Try higher extension temperatures to reduce RNA secondary structure. Add actinomycin D to the reverse transcription buffer. Add more reverse transcriptase or try a new preparation of reverse transcription buffer. Try a different RNA preparation, which may contain fewer contaminants that inhibit the reverse transcriptase.

Problem: (Step 33): There is a blank gel image, no primer signal, and no cDNA products. Solution: Consider the following:

1. Yield of radiolabeled primer may have been low. Radioactivity in primer preparation may have been due primarily to unincorporated nucleotides. Run an aliquot of radiolabeled primer on the gel and expose the gel to film to determine if preparation contains radiolabeled primer. If not, proceed as described above for poor yield of radiolabeled primer.

2. Radiolabeled primer may have been lost during an ethanol precipitation step. Carefully monitor amount of radioactivity in supernatants and pellets during each precipitation.

Primer extension (Fig. 1) was first described by P.K. Ghosh and S.M. Weissman (Ghosh et al. 1978). It was previously recommended as the first method to try when attempting to identify the initiation site for a new gene. With improvements in the $5^{\prime}$ RACE procedure, this is no longer the case; however, relative to RNase protection and S1 nuclease analysis, primer extension is easier and faster to perform. The protocol described here was adapted from McKnight and Kingsbury (1982). It can be completed in $\sim 5 \mathrm{~h}$, and the only specific reagents required are an mRNA sample and a radiolabeled oligonucleotide primer complementary to a sequence within the gene. With a primer that efficiently hybridizes to the mRNA, this method can be extremely sensitive, although less sensitive than $5^{\prime}$ RACE. An additional advantage of primer extension is that it can provide an attractive and quantitative alternative to real-time RT (reverse transcription)-PCR (polymerase chain reaction) and northern blots for routinely monitoring gene expression.

A disadvantage of the primer extension protocol is that it can be difficult to find a primer that works well for a new gene. Moreover, background bands caused by premature termination of reverse transcription (because of RNA secondary structure) often appear, which can make it difficult to determine unambiguously the location of the start site. For some mRNAs, such as those associated with CpG islands, reverse transcription may be particularly inefficient. Because of these limitations, we recommend that start site-mapping results obtained using the primer extension method be confirmed using another method, such as RNase protection. 
M.F. Carey et al.

\section{Design of Oligonucleotide Primers}

Oligonucleotide primers of many different lengths can work well for primer extension. Before synthetic oligonucleotides became widely available, single-stranded primers derived from restriction fragments of 100 nucleotides or more were used successfully. Primers of this length are rarely used today because synthetic oligonucleotides are now inexpensive and easy to obtain. Synthetic oligonucleotides of nine nucleotides are sufficient for hybridization and extension, but are not used for this method because the hybridization lacks specificity and efficiency. Oligonucleotides of 20-25 bp typically yield excellent results. Several software programs are available for designing primers with length and melting temperature $\left(T_{\mathrm{m}}\right)$ in mind. The Primer3 program (http://frodo.wi.mit.edu) is one such program preferred by many researchers. Commercially available programs include PrimerSelect from DNASTAR, Inc. (http://www.dnastar.com/t-sub-products-lasergene-primerselect.aspx) and Oligo Primer Analysis Software from Molecular Biology Insights (http://www.oligo.net/).

Although computer programs are recommended for the design of primers, the practical success obtained with different primers can be variable. If less-than-ideal results are obtained with an initial primer, one or even several additional primers complementary to other sequences near the $5^{\prime}$ end of the mRNA should be tested. It is not known why the quality of the data obtained with different primers possessing similar $T_{\mathrm{m}}$ values can be widely variable, but differences in primer labeling efficiency or mRNA secondary structure might be responsible.

To localize a transcription start site accurately, it is best for the $5^{\prime}$ end of the primer to anneal to a position on the mRNA that is expected to be about 50-150 nucleotides from the mRNA start site. This length allows the resulting cDNA products to be measured accurately on a denaturing polyacrylamide gel if electrophoresed adjacent to a DNA sequencing ladder. cDNA products shorter than $50 \mathrm{bp}$ are undesirable because reverse transcriptase reactions sometimes terminate or pause after extending a 
very short distance, resulting in strong background bands that are 10-20 bp longer than the primer. Additionally, reverse transcriptase will sometimes synthesize a copy of the primer, leading to the socalled "primer dimer" artifact. If the cDNA synthesized is at least 50 nucleotides (e.g., a 20-nucleotide primer plus a 30-nucleotide extension), it will usually be well-separated from the majority of these background bands. cDNA products longer than $150 \mathrm{bp}$ can often be obtained, but the efficiency of reverse transcriptase extension decreases with distance because of pausing and premature termination. Furthermore, the longer the extension product, the more difficult it will be to determine an accurate size, because of the decreased resolution of large fragments on a denaturing polyacrylamide sequencing gel.

\section{Primer Annealing and Reverse Transcription}

For each primer tested, the annealing conditions must be determined empirically because the temperatures predicted on the basis of nucleotide content are not always accurate. For the primer extension procedure described here, the annealing reaction is performed in $250 \mathrm{~mm} \mathrm{KCl}$. At this salt concentration, suggested temperatures to test are $37^{\circ} \mathrm{C}, 45^{\circ} \mathrm{C}, 60^{\circ} \mathrm{C}$, and $68^{\circ} \mathrm{C}$. One can also heat the annealing reaction to $68^{\circ} \mathrm{C}$ in a temperature block and then allow it to cool slowly to room temperature.

The primer extension assay can be performed by following any of a variety of protocols that make use of different reverse transcriptases expressed in E. coli or purified from retrovirus-infected cells. The extension reaction described here uses MMLV reverse transcriptase that had been cloned and expressed in Escherichia coli. MMLV reverse transcriptase contains an RNase $\mathrm{H}$ activity that can lead to enhanced background, but modified reverse transcriptases lacking RNase $\mathrm{H}$ activity are available from Invitrogen (e.g., SuperScript II RT and SuperScript III RT). SuperScript III RT contains additional mutations that increase thermal stability and half-life, allowing extension reactions to be performed at elevated temperatures, thereby reducing problems associated with RNA secondary structures. Extension reactions can be carried out using other reverse transcriptases, including avian reverse transcriptase, but the reaction conditions are different and more sensitive to variations in $\mathrm{pH}$.

\section{Example of Data Analysis}

For the terminal transferase (TdT) primer extension example shown in Figure 2B, three different primers were tested (Smale and Baltimore 1989). The $5^{\prime}$ end of one primer hybridizes at a location that is $87 \mathrm{bp}$ downstream of the transcription start site, whereas the $5^{\prime}$ ends of the other two primers hybridize 201 and 221 bp downstream of the start site. The large excess of free primer, which migrates very rapidly through the gel, was removed from the bottom of the autoradiograph shown in this figure. To confirm that the primer was in considerable excess, it is beneficial to retain the free primer on the bottom of the gel. The largest extension products observed with each primer map to a single transcription start site. The second and third primers hybridize somewhat farther from the transcription start site than was recommended above (201 and 221 bp rather than 50-150 bp). Nevertheless, these primers were efficiently extended to the $5^{\prime}$ end of the mRNA in this experiment. In other experiments in which extension efficiency was lower, the full-length extension products were less abundant and accompanied by shorter, partial extension products (data not shown). The signal intensities obtained with the three different primers, although comparable on this gel, were variable, with the amounts of reaction product normalized to generate bands of similar intensity on the autoradiograph. Variability between primers can result from differences in the efficiency of labeling or annealing.

For each primer, total cellular mRNA was tested from two murine cell lines that express the TdT gene and from one murine cell line that does not express the gene as a negative control. The use of a negative control from the same species can be invaluable. Background bands are often observed that result from hybridization of the primer to unrelated RNAs. The presence of these bands in the negative control lane reveals that they are unrelated to the tissue-specific transcript of interest. Two examples of 
A

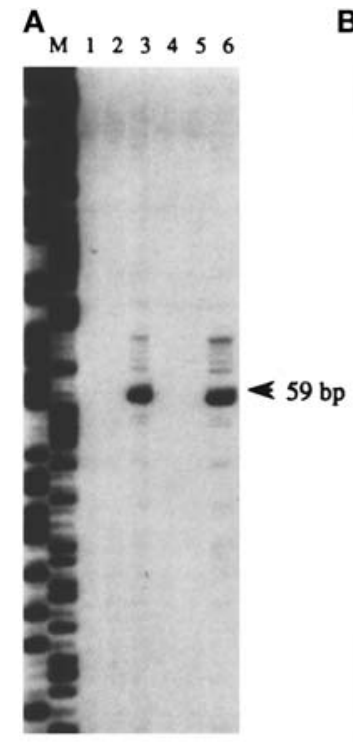

B

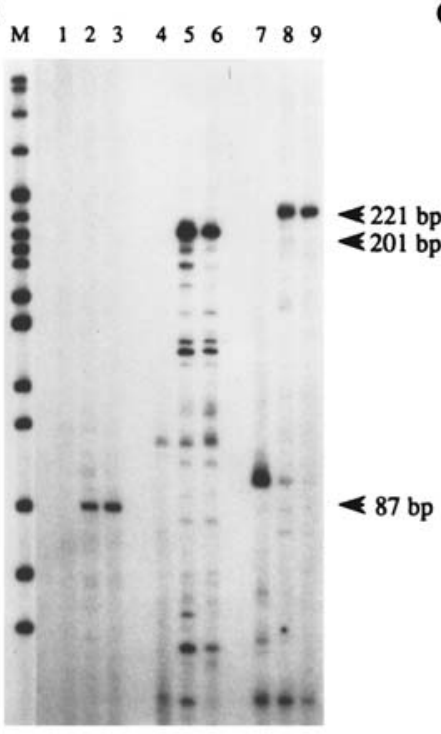

C ,

$\begin{array}{llll}1 & 2 & 3 & M\end{array}$
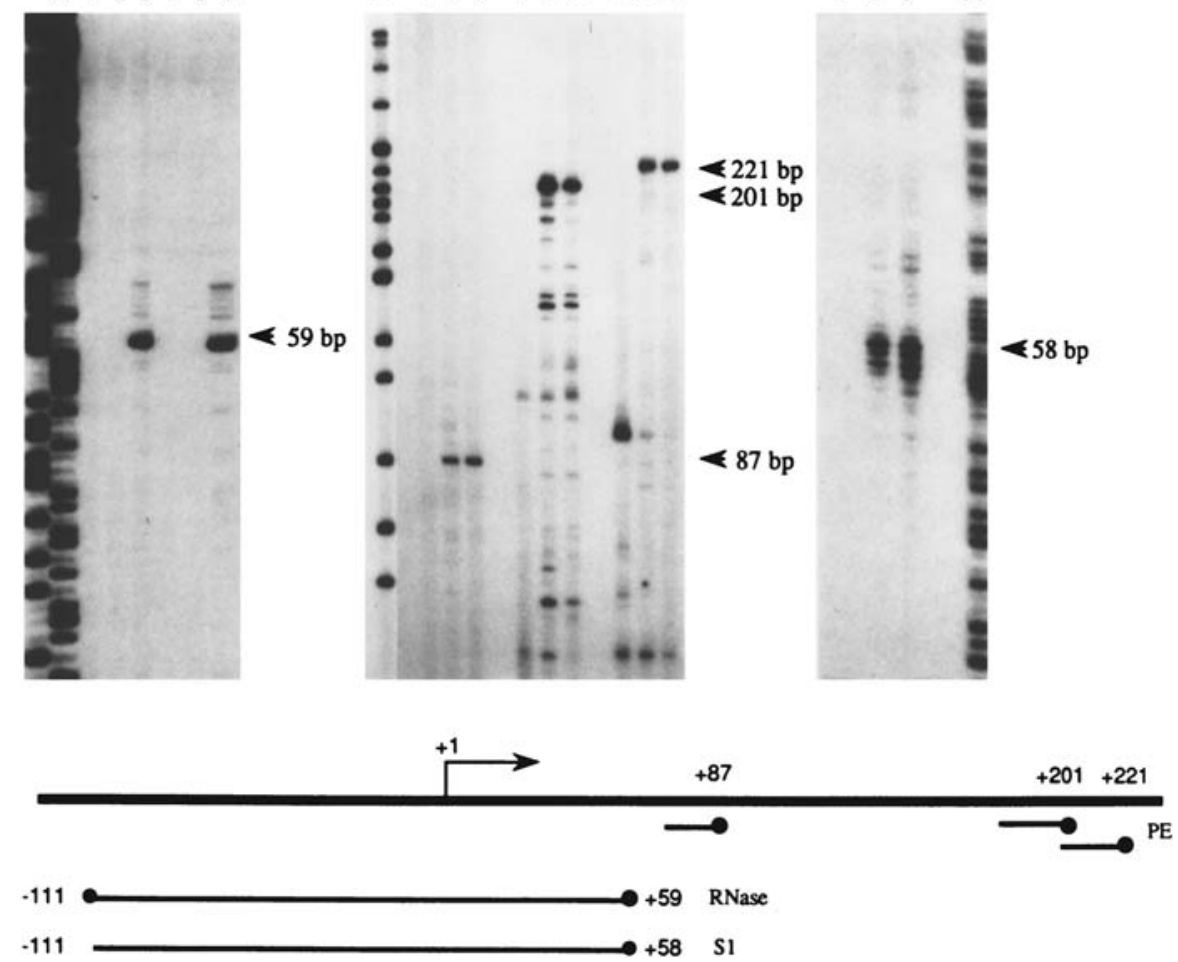

FIGURE 2. Results from RNase protection, primer extension, and S1 nuclease experiments to map the transcription initiation site for the murine terminal transferase (TdT) gene. (A) The RNase protection assay was performed with cytoplasmic RNA from two cell lines that express the TdT gene (lanes 3 and 6) and from four cell lines that lack expression (lanes 1, 2, 4, and 5). The labeled probe extended from nucleotide +59 to -111 . The expected product is 59 nucleotides. Sequencing markers are also shown (M). (Reprinted, with permission, from Lo et al. 1991.) (B) The primer extension assay was performed with cytoplasmic RNA from two cell lines that express the TdT gene (lanes 2, 3, 5, 6, 8, and 9) and from one line that lacks expression (lanes 1, 4, and 7). Three different primers were used whose $5^{\prime}$ ends hybridize 87 (lanes 1-3), 201 (lanes 4-6), or 221 (lanes 7-9) bp downstream of the anticipated start site. Markers (M) are $5^{\prime}$-end-labeled Mbol restriction fragments from the plasmid pBR322. (C) The S1 nuclease assay was performed with cytoplasmic RNA from two cell lines that express the TdT gene (lanes 2 and 3) and from one line that lacks expression (lane 1). The labeled probe extended from nucleotide +58 to nucleotide -111 . The expected product is 58 nucleotides. Sequencing markers are shown $(M)$. ( $B$, Reprinted, with permission of Elsevier, from Smale and Baltimore 1989.)

this type of background band are observed with the second primer and two with the third primer, with one example in each case in the middle section of the autoradiograph and one at the bottom. The third primer yielded an unusually strong background band in the negative control lane that was much less abundant in the positive lanes and was not detected with the other primers. The absence of this band with the second primer suggests that it was caused by an unrelated transcript to which the third primer fortuitously hybridized. Apparently, this transcript was strongly expressed only in the negative control cell line.

Other background bands that are evident (primarily with the second primer) are likely to have resulted from reverse transcriptase pausing during extension on full-length mRNAs. Background bands can also be caused by severe mRNA degradation, hybridization to unrelated transcripts as described above, or the presence of multiple transcription start sites. A primary limitation of the primer extension procedure is that background bands like those observed with the second primer are quite common; it is very difficult to determine which bands correspond to authentic transcription start sites and which are experimental artifacts. For the TdT gene, the use of multiple primer extension primers and subsequent confirmation by RNase protection (Fig. 2A) and S1 nuclease (Fig. 2C) analyses allowed a precise determination of the authentic mRNA start site. 
Primer Extension (PE) Buffer (5×)

5 mм EDTA

$1.25 \mathrm{M} \mathrm{KCl}$

50 mм Tris-HCl (pH 7.5)

Reverse Transcription (RT) Buffer

$100 \mu \mathrm{g} / \mathrm{mL}$ BSA (bovine serum albumen)

$0.5 \mathrm{~mm}$ dCTP, dGTP, dATP, dTTP

$10 \mathrm{~mm}$ DTT (dithiothreitol)

$25 \mathrm{~mm} \mathrm{KCl}$

$3.5 \mathrm{~mm} \mathrm{MgCl}_{2}$

$50 \mathrm{~mm}$ Tris- $\mathrm{HCl}$ (7.5)

Store at $-20^{\circ} \mathrm{C}$.

\section{STE Buffer for Primer Extension}

10 mм EDTA

$100 \mathrm{~mm} \mathrm{NaCl}$

20 mm Tris- $\mathrm{HCl}$ (pH 7.5)

T4 PNK Buffer (10×)

$50 \mathrm{~mm}$ DTT (dithiothreitol)

1 mM EDTA (pH 8.0)

$0.1 \mathrm{M} \mathrm{MgCl}_{2}$

$1 \mathrm{~mm}$ spermidine $\mathrm{HCl}$

0.5 м Tris- $\mathrm{HCl}$ (pH 7.6)

\section{REFERENCES}

Ghosh PK, Reddy VB, Swinscoe J, Lebowitz P, Weissman SM. 1978. Heterogeneity and $5^{\prime}$-terminal structures of the late RNAs of simian virus 40. J Mol Biol 126: 813-846.

Lo K, Landau NR, Smale ST. 1991. LyF-1, a transcriptional regulator that interacts with a novel class of promoters for lymphocyte-specific genes. Mol Cell Biol 11: 5229-5243.

McKnight SL, Kingsbury R. 1982. Transcriptional control signals of a eukaryotic protein-coding gene. Science 217: 316-324.
Sambrook J, Russell DW. 2001. Molecular cloning: A laboratory manual, 3rd ed. Cold Spring Harbor Laboratory Press, Cold Spring Harbor, New York.

Sambrook J, Russell DW. 2006. Purification of radiolabeled oligonucleotides by precipitation with ethanol. Cold Spring Harb Protoc doi: 10.1101/ pdb.prot3490.

Smale ST, Baltimore D. 1989. The "initiator" as a transcription control element. Cell 57: 103-113. 


\section{The Primer Extension Assay}

Michael F. Carey, Craig L. Peterson and Stephen T. Smale

Cold Spring Harb Protoc; doi: 10.1101/pdb.prot071902

\begin{tabular}{|c|c|}
\hline $\begin{array}{r}\text { Email Alerting } \\
\text { Service }\end{array}$ & Receive free email alerts when new articles cite this article - click here. \\
\hline $\begin{array}{l}\text { Subject } \\
\text { Categories }\end{array}$ & $\begin{array}{l}\text { Browse articles on similar topics from Cold Spring Harbor Protocols. } \\
\text { Molecular Biology, general (1293 articles) } \\
\text { mRNA (132 articles) } \\
\text { RNA (317 articles) }\end{array}$ \\
\hline
\end{tabular}

